
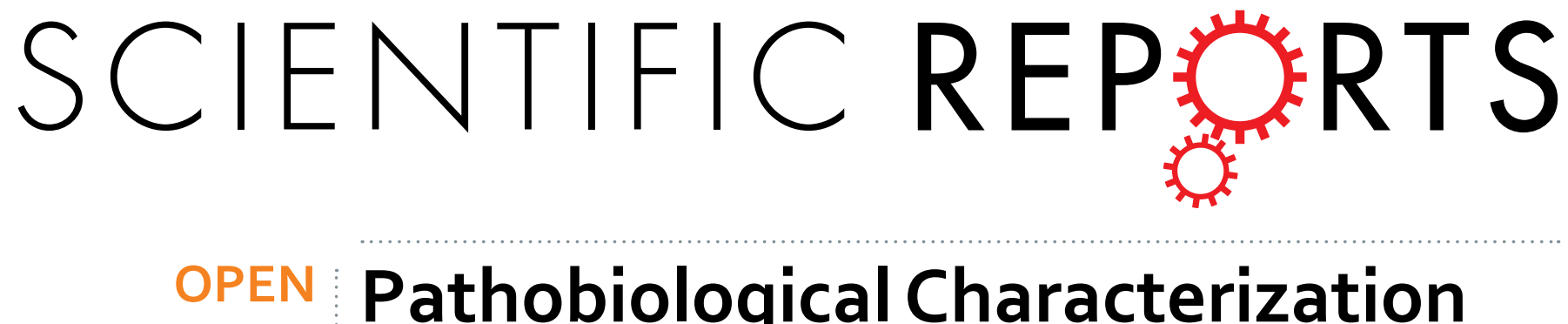

\title{
Pathobiological Characterization of a Novel Reassortant Highly Pathogenic H5N1 Virus Isolated in
}

Received: 06 November 2015

Accepted: 29 February 2016

Published: 18 March 2016
British Columbia, Canada, 2015

Yohannes Berhane ${ }^{1,2}$, Darwyn Kobasa ${ }^{3,4}$, Carissa Embury-Hyatt ${ }^{1}$, Brad Pickering ${ }^{1}$, Shawn Babiuk ${ }^{1,5}$, Tomy Joseph ${ }^{6}$, Victoria Bowes ${ }^{6}$, Mathew Suderman ${ }^{1}$, Anders Leung ${ }^{3}$, Colleen Cottam-Birt ${ }^{1}$, Tamiko Hisanaga ${ }^{1}$ \& John Pasick ${ }^{1}$

In the current study, we describe the pathobiologic characteristics of a novel reassortant virus - A/ chicken/BC/FAV-002/2015 (H5N1) belonging to clade 2.3.4.4 that was isolated from backyard chickens in British Columbia, Canada. Sequence analyses demonstrate PB1, PA, NA and NS gene segments were of North American lineage while PB2, HA, NP and M were derived from a Eurasian lineage H5N8 virus. This novel virus had a 19 amino acid deletion in the neuraminidase stalk. We evaluated the pathogenic potential of this isolate in various animal models. The virus was highly pathogenic to mice with a $L_{50}$ of 10 plaque forming units (PFU), but had limited tissue tropism. It caused only subclinical infection in pigs which did result in seroconversion. This virus was highly pathogenic to chickens, turkeys, juvenile Muscovy ducks (Cairnia moschata foma domestica) and adult Chinese geese (Anser cynoides domesticus) causing a systemic infection in all species. The virus was also efficiently transmitted and resulted in mortality in naïve contact ducks, geese and chickens. Our findings indicate that this novel H5N1 virus has a wide host range and enhanced surveillance of migratory waterfowl may be necessary in order to determine its potential to establish itself in the wild bird reservoir.

In December 2014, a highly pathogenic avian influenza (HPAI) outbreak due to a novel reassortant H5N2 virus was reported near Abbotsford, British Columbia ${ }^{1}$. This outbreak was extraordinary in that it was the first reported case involving the transcontinental spread of Eurasian A/Goose/Guangdong/1/96- like HPAI H5N1 lineage (Gs/Gd like-lineage) viruses to North America. Eurasian Gs/Gd like-lineage HPAI H5N1 first emerged in domestic geese in south-eastern China in 1996 eventually spreading to infect domestic poultry and wild birds in Asia, Europe and Africa ${ }^{2-5}$. Currently viruses of the $\mathrm{Gs} / \mathrm{Gd}$ like-lineage have become endemic in poultry in a number of countries in Asia and Africa. Since their emergence, Gs/Gd like-lineage H5N1 viruses have caused huge economic losses to the poultry industry as a result of mortalities and stamping out activities ${ }^{3,6,7}$. In addition, these viruses as of 15 November, 2015, have been associated with 844 human cases and an associated case fatality rate of $\sim 53 \%$ resulting primarily from direct contact with infected birds (http://www.who.int/influenza/human_animal_ interface/H5N1_cumulative_table_archives/en/). Since 2003 the hemagglutinin (HA) gene of Gs/Gd like-lineage $\mathrm{H} 5 \mathrm{~N} 1$ viruses has undergone continual evolutionary divergence resulting in the establishment of distinct phylogenetic clades $^{8}$. This prompted the WHO/OIE/FAO H5N1 Evolution Working Group in $2008^{9}$ to establish a system of classifying these divergent groups.

Avian influenza (AI) virus surveys and surveillance have been conducted in North American wild waterfowl populations for a number of years; one of the objectives being to assess whether Gs/Gd-like HPAI H5N1 viruses could be introduced to the Americas via intermingling of long range migratory birds along East Asian-Australasian, West Pacific and Pacific Americas migratory flyways. Although there was no evidence for

${ }^{1}$ Canadian Food Inspection Agency, National Centre for Foreign Animal Disease, Winnipeg, Manitoba, Canada R3E 3M4. ${ }^{2}$ Department of Animal Science, University of Manitoba, Winnipeg, Canada. ${ }^{3}$ Public Health Agency of Canada, National Microbiology Laboratory, 1015 Arlington Street, Winnipeg, Manitoba, Canada. ${ }^{4}$ Department of Medical Microbiology, University of Manitoba, Winnipeg, Canada . ${ }^{5}$ Department of Immunology, University of Manitoba, Winnipeg, Canada . ${ }^{6}$ Animal Health Centre, Ministry of Agriculture, Abbotsford, British Columbia, Canada V3G 2 M3. Correspondence and requests for materials should be addressed to J.P. (email: John.Pasick@inspection.gc.ca) 


\begin{tabular}{|c|c|c|}
\hline Segment/Lineage & \% Nucleotide Identity similarity & $\%$ Protein identity similarity \\
\hline $\mathrm{PB} 2 /$ Eurasian & A/gyrfalcon/Washington/41088-6/2014(H5N8) 2276/2280 (99\%) & A/gyrfalcon/Washington/41088-6/2014(H5N8) 758/759 (100\%) \\
\hline PB1/North American & $\begin{array}{l}\text { A/American green-winged teal/Washington/195750/2014(H5N1) } \\
\text { 2270/2274 (99\%) }\end{array}$ & $\begin{array}{l}\text { A/American green-winged teal/Washington/195750/2014(H5N1) 756/757 } \\
(99 \%)\end{array}$ \\
\hline PA/North American & $\begin{array}{l}\text { A/American green-winged teal/Washington/195750/2014(H5N1) } \\
2147 / 2151(99 \%)\end{array}$ & A/mallard/Alaska/44430-148/2008(H4N6) 715/716 (99\%) \\
\hline HA/Eurasian & $\begin{array}{l}\text { A/American green-winged teal/Washington/195750/2014(H5N1) } \\
1700 / 1704(99 \%)\end{array}$ & A/gyrfalcon/Washington/41088-6/2014(H5N8) 566/567 (99\%) \\
\hline $\mathrm{NP} /$ Eurasian & $\begin{array}{l}\text { A/American green-winged teal/Washington/195750/2014(H5N1) } \\
1496 / 1497(99 \%)\end{array}$ & $\begin{array}{l}\text { A/American green-winged teal/Washington/195750/2014(H5N1) 498/498 } \\
(100 \%)\end{array}$ \\
\hline NA/North American & $\begin{array}{l}\text { A/American green-winged teal/Washington/195750/2014(H5N1) } \\
1312 / 1314(99 \%)^{*}\end{array}$ & $\begin{array}{l}\text { A/American green-winged teal/Washington/195750/2014(H5N1) 463/485 } \\
(96 \%)\end{array}$ \\
\hline M/ Eurasian & $\begin{array}{l}\text { A/American green-winged teal/Washington/195750/2014(H5N1) 987/987 } \\
(100 \%)\end{array}$ & $\begin{array}{l}\text { A/American green-winged teal/Washington/195750/2014(H5N1) M1 - 97/97 } \\
(100 \%) \& M 2-252 / 252(100 \%)\end{array}$ \\
\hline NS/North American & $\begin{array}{l}\text { A/American green-winged teal/Washington/195750/2014(H5N1) 850/850 } \\
(100 \%)\end{array}$ & $\begin{array}{l}\text { A/American green-winged teal/Washington/195750/2014(H5N1) NS2 - } \\
\text { 121/121 (100\%); NS1 - 230/230 (100\%) }\end{array}$ \\
\hline
\end{tabular}

Table 1. Percent nucleotide and protein identity between FAV-002/H5N1 and top NCBI BLAST matches for eight gene segments. ${ }^{\star}$ Excluding the 57 nucleotide deletion in the stalk region.

Gs/Gd-like HPAI H5N1 introduction, some studies did show evidence of limited intermingling of Eurasian and American AI viruses along these migratory flyways ${ }^{10-15}$.

This changed with the recent emergence of Gs/Gd-like H5N8 viruses belonging to clade 2.3.4.4. Early in 2014, outbreaks of HPAI H5N8 virus were reported in China, South Korea, Japan and Russia where migratory birds were suspected to have played a key role in the introduction of this virus to domestic poultry ${ }^{16}$. During the fall of 2014, this H5N8 virus spread to Western European countries causing outbreaks in Germany, the Netherlands, England and Italy ${ }^{17}$. In December 2014, an outbreak of HPAI caused by a novel reassortant H5N2 virus with a Gs/ Gd-like HA gene belonging to clade 2.3.4.4 was reported in the lower Fraser Valley of British Columbia, Canada ${ }^{1}$. This virus consisted of a mixture of gene segments of Eurasian HPAI H5N8 virus and North American lineage low pathogenic virus origin. This HPAI H5N2 virus caused outbreaks in 12 different poultry premises in the lower Frazer Valley (data not shown). A wholly Eurasian H5N8 virus was subsequently detected in wild waterfowl in the same area. Wholly Eurasian $\mathrm{H} 5 \mathrm{~N} 8$ and reassortant $\mathrm{H} 5 \mathrm{~N} 2$ viruses were eventually detected in captive birds, wild birds and backyard domestic poultry flocks in Washington, Oregon and California (USDA, APHIS data base). This was followed by outbreaks of $\mathrm{H} 5 \mathrm{~N} 2$ and $\mathrm{H} 5 \mathrm{~N} 8$ in commercial domestic poultry, initially in states located along the Pacific flyway, with further outbreaks of H5N2 in states located along Central and Mississippi flyways ${ }^{18}$. In early April 2015, three HPAI H5N2 outbreaks in domestic poultry ( 2 turkey and 1 chicken farms) were reported in Oxford county, Ontario, Canada. All three of these farms were located on the extreme eastern edge of the Mississippi flyway.

On December 24, 2014, a second novel reassortant HPAI H5N1 virus was isolated from a green-winged teal (Anas Crecca) shot by a hunter in Whatcom County, Washington ${ }^{19}$. In February 2015, a similar HPAI H5N1 virus was isolated from backyard chicken layer flock in the lower Fraser Valley, British Columbia. Although animal studies have been conducted in a number of different species using Eurasian clade 2.3.4.4 H5N8 viruses ${ }^{6,7,20,21}$, little was known about the pathogenic potential of this novel HPAI H5N1 in different species of birds and mammals. While a closely related novel H5N1 virus, A/American green-winged teal/Washington/195750/2014 (AGT/ $\mathrm{H} 5 \mathrm{~N} 1$ ), had been isolated from a hunter killed green-winged teal ${ }^{19}$, no information was available regarding the clinical and pathological presentation of the affected animal. Previous reports involving natural or experimental infections with Gs/Gd-like HPAI H5N1 viruses showed that they could replicate and efficiently transmit in ducks, however, the pathogenicity ranged widely from sub-clinical infection to clinical disease with mortality.

Here we assess the pathobiological characteristics of a novel reassortant HPAI H5N1 virus that was isolated from a backyard chicken flock in domestic gallinaceous poultry, domestic geese, domestic ducks, pigs and mice. The aim of this study was to help evaluate the risk associated with this new virus to birds and mammals while also gaining a clearer understanding of the infectivity, pathogenicity and clinical signs in different species.

\section{Results}

Genetic characterization of the novel HPAI H5N1 reassortant virus. The full genome sequence of the virus was acquired directly from lung tissue that was collected from clinically sick or dead chickens as well as from a virus isolate obtained after passaging in embryonated chicken eggs (FAV-002/H5N1). Alignment of full genome sequences obtained from the 3 tissue samples and the virus isolate were $99.8 \%$ to $100 \%$ identical to one another. The full genome sequence of FAV-002/H5N1 has been deposited in the NCBI data base with accession numbers KP892988 to KP892995. Sequence analyses demonstrated that 4 gene segments - basic polymerase 1 (PB1), acidic polymerase (PA), neuraminidase (NA) and non-structural (NS) were derived from an unknown virus of North American lineage; the basic polymerase 2 (PB2), hemagglutinin (HA), nucleoprotein (NP) and matrix (M) segments were derived from a Eurasian lineage $\mathrm{H} 5 \mathrm{~N} 8$ virus. The derived $\mathrm{HA}_{0}$ cleavage site NSPLRERRRKR/GLF was found to be consistent with other Gs/Gd like-lineage Eurasian H5 subtype viruses belonging to clade 2.3.4.4. Top NCBI BLAST matches for each gene segment of FAV-002/H5N1 are summarized in Table 1 . When compared to AGT/H5N1, its closest match in the NCBI database, FAV-002/H5N1 had a number of non-synonymous mutations. These included: a V to A substitution involving the $14^{\text {th }}$ amino acid of the signal 


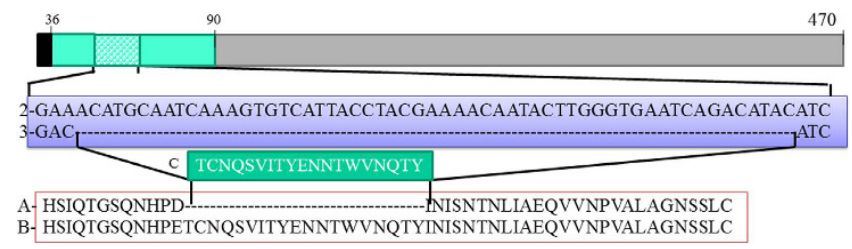

Figure 1. Schematic description of full neuraminidase type 1 protein -470 amino acids (1). The NA domain corresponding to the stalk region is highlighted in green (36-90 AA) and the deletion of 19 AA in FAV$002 / \mathrm{H} 5 \mathrm{~N} 1$ is highlighted in green/white squares. The globular head is highlighted in grey and the transmembrane domain in black. Alignment of the nucleotide sequence of the stalk region which is deleted in FAV-002/H5N1

(3) and AGT/H5N1 (2). Alignment of the protein sequence stalk region of FAV-002/H5N1 (A) and AGT/H5N1

(B). The deleted part of the NA stalk of FAV-002/H5N1 (C) is highlighted in green box.

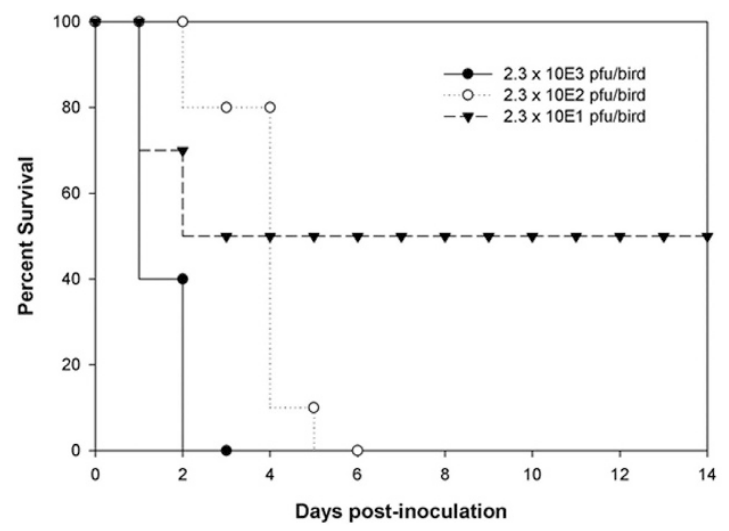

Figure 2. The survival curves for SPF chickens infected with three different dilutions of FAV-002/H5N1. The $\mathrm{LD}_{50}$ of FAV-002/H5N1 in chickens was determined to be $23 \mathrm{PFU}$.

peptide of the HA precursor and E501D in the HA 2 ; 21 T in NA; L522M in PB2; E78D in PB1; and H271P and D347N in PA. No mutations were observed in the NP, M and NS gene segments.

The most notable change in FAV-002/H5N1 involved the NA protein which had a 19 AA deletion (48-TCNQSVITY ENNTWVNQTY-66) in its stalk when compared to AGT/H5N1 (Fig. 1). This 19 AA deletion in the NA of FAV-002/H5N1 compared to AGT/H5N1, led us to further investigate whether the infected backyard flock contained a mixed population of $\mathrm{H} 5 \mathrm{~N} 1$ viruses with deleted and non-deleted NA stalk regions. Following deep sequencing of the NA gene amplified from the 12 original lung tissue specimens collected from the backyard flock as well as the FAV-002/H5N1 isolate, no full length NA genes were found.

Pathobiological properties of FAV-002/H5N1 in domestic poultry and waterfowl. Chickens. The intravenous pathogenicity index (IVPI) of FAV-002/H5N1 was determined to be 2.97 indicating a HPAI virus. IVPI scores can range from 0 where none of the birds exhibit signs of disease during the 10 day observation period, to 3.00 where all of the birds die within the first 24 hours post-inoculation. The threshold score for considering a virus to be highly pathogenic is 1.2 . The $\mathrm{LD}_{50}$ of FAV-002/H5N1 in chickens was determined to be 23 plaque forming units (PFU) (Fig. 2).

Turkeys. FAV-002/H5N1 was very lethal to juvenile domestic turkeys. Four turkeys died at 2 dpi following intranasal inoculation with $10^{3}$ PFU of virus and 1 contact turkey died 24 hrs post-contact without showing any clinical signs. The remaining turkeys were very sick and showed clinical signs that included ruffled feathers, drooped wings, depression, labored breathing, oral discharge, and neurological abnormalities such as ataxia and head shaking. Some of the feces $(25 \%)$ contained blood. The remaining turkeys died or were euthanized due to severe illness by $4 \mathrm{dpi}$. The major postmortem findings included fibrinous pleuritis in lungs, swollen kidneys, mottled spleens with large white necrotic areas, large white focal necrotic areas in the pancreas, and an enlarged friable liver with white areas of necrosis or pinpoint areas of hemorrhage. The survival curve for the inoculated and contact turkeys is shown in Fig. 3.

Chinese Geese. FAV-002/H5N1 was moderately pathogenic to Chinese geese following inoculation by oronasal and cloacal routes. Clinical signs first appeared in the infected geese at $3 \mathrm{dpi}$ and lasted until $9 \mathrm{dpi}$. The clinical signs included green feces, trembling, depression/lethargy, ruffled feathers, huddling, labored breathing, inability to walk when approached and drooping of the wings. Seven of the nine inoculated geese showed signs with two of the geese dying at $5 \mathrm{dpi}$. Similar clinical signs were also observed in the contact geese starting on the $3^{\text {rd }}$ day post-contact $(\mathrm{dpc})$. Of the contact geese four of the five died or were euthanized when moribund by $11 \mathrm{dpc}$. All five contact chickens died or were euthanized when moribund by $5 \mathrm{dpc}$. Gross lesions in the geese included 


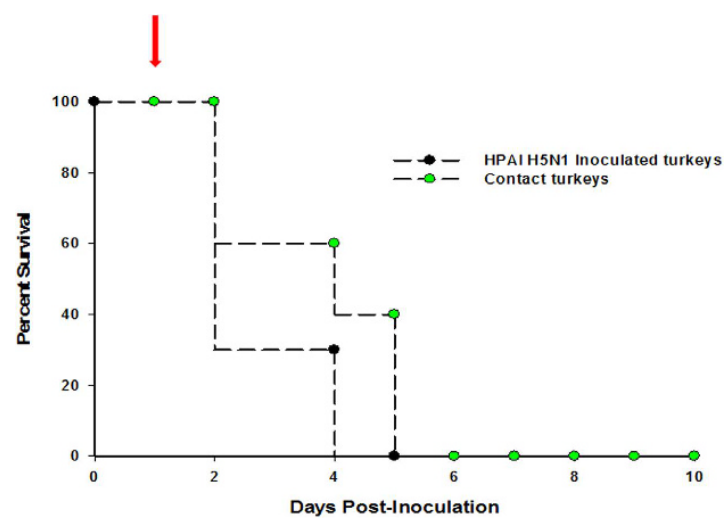

Figure 3. The survival curves for domestic juvenile turkeys infected with 1000 PFU of FAV-005/H5N1 and naïve contact turkeys that were placed among the infected $24 \mathrm{hrs}$ after infection. The arrow indicates when naïve contact turkeys were placed among the infected turkeys at $24 \mathrm{hrs}$ post-infection.
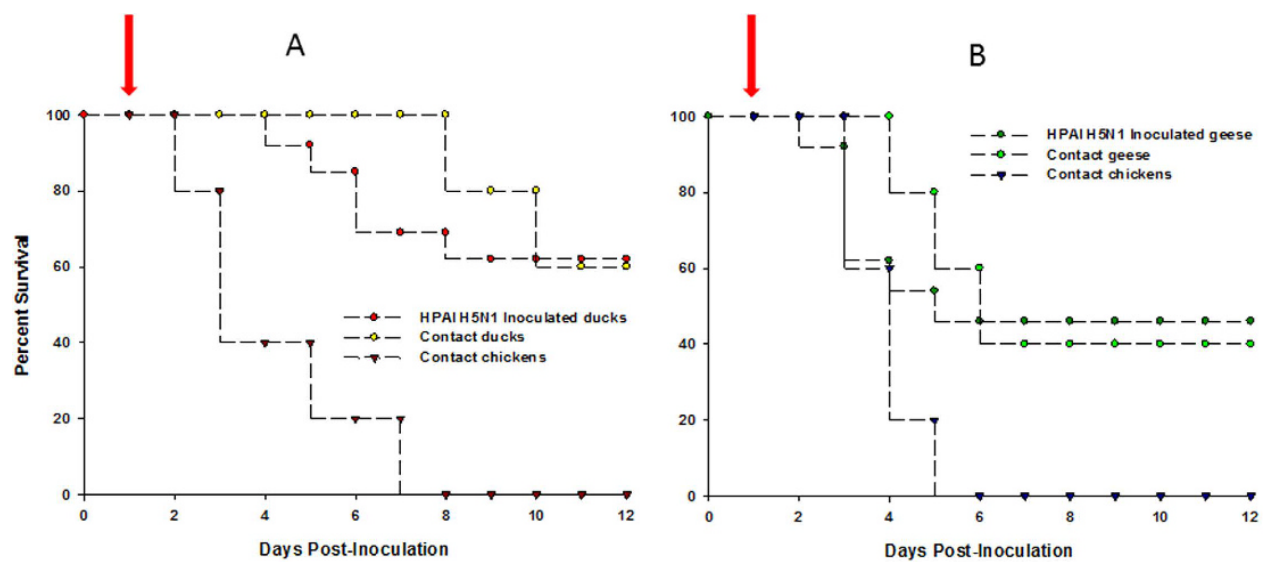

Figure 4. Survival curves of birds infected with 10,000 PFU of FAV-002/H5N1 and their contacts.

(A) shows the survival curves of Muscovy ducks that were infected with 10,000 PFU of FAV-002/H5N1. The arrow indicates when Muscovy ducks and chickens that were placed among the infected ducks at 24 hrs postinfection. (B) shows the survival curves of Chinese geese that were infected with 10,000 PFU of FAV-002/H5N1 and contact Chinese geese and chickens that were placed in the same animal cubicle at $24 \mathrm{hrs}$ post-infection (arrow).

conjunctivitis; pinpoint areas of hemorrhage on the myocardium, liver and abdominal fat; focal areas of necrosis on the pancreas; and hemorrhagic intestinal content with a hyperemic mucosal surface. The lungs were discolored and covered with a layer of fibrin and the air sacs were very thick. The female geese had egg yolk peritonitis. The spleens were enlarged and dark with a marbled appearance. Figure $4 \mathrm{~A}$ shows the survival curves for Chinese geese that were infected with $10,000 \mathrm{PFU}$ of FAV-002/H5N1 and contact Chinese geese and chickens that were allowed to co-mingle $24 \mathrm{hrs}$ post-infection.

Muscovy ducks. The clinical signs in the Muscovy ducks were milder, but of a more protracted nature when compared with the geese. Clinical signs were first observed on the $3^{\text {rd }}$ day after infection and lasted for up to 14 days. Clinical signs ranged from depression and open mouth breathing to neurological signs in some of the animals. The neurological signs appeared after $7 \mathrm{dpi}$ and included circling, head twitching and ataxia and most of these birds were able to recover from the disease. Of the fifteen inoculated ducks eleven showed clinical signs and four died or were euthanized. Two of the five contact ducks presented with clinical signs both of which died at 2 and $8 \mathrm{dpc}$ respectively. All five contact chickens that were co-housed with the ducks to assess transmission died or were euthanized when moribund; the first died at $3 \mathrm{dpc}$ and the last at $8 \mathrm{dpc}$. The major postmortem findings were pulmonary edema and fibrinous pleuritis in lungs and hyperemic tracheas. In some ducks, the spleens were dark, enlarged and had white necrotic areas. The pancreas exhibited large white patches of necrotic foci and the liver had multifocal small white areas of necrosis. Figure $4 \mathrm{~B}$ illustrates the survival curves for Muscovy ducks that were infected with 10,000 PFU of FAV-002/H5N1 along with contact Muscovy ducks and chickens that were allowed to co-mingle beginning at $24 \mathrm{hrs}$ post-infection. 
A

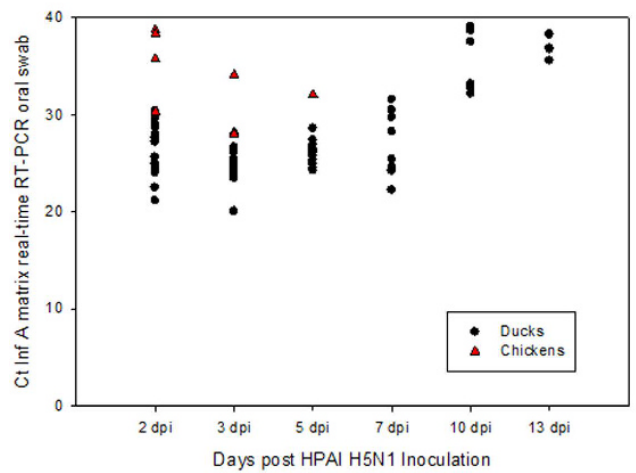

B

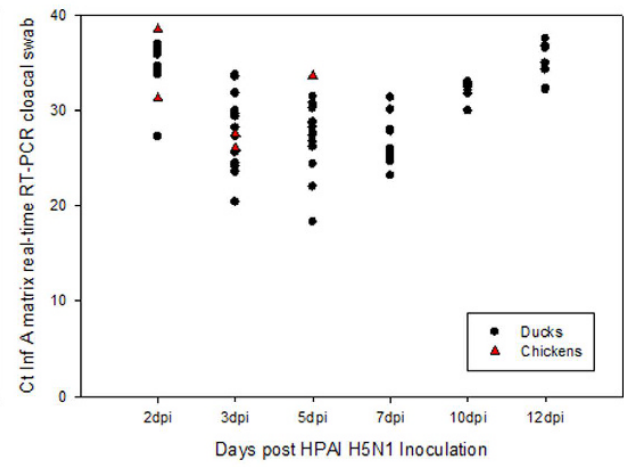

Figure 5. Virus shedding patterns of Muscovy ducks infected with 10,000 PFU of FAV-002/H5N1. Total RNA was extracted from oral (A) and cloacal (B) specimens and was tested using the avian influenza matrix based real time RT-PCR assay.

A

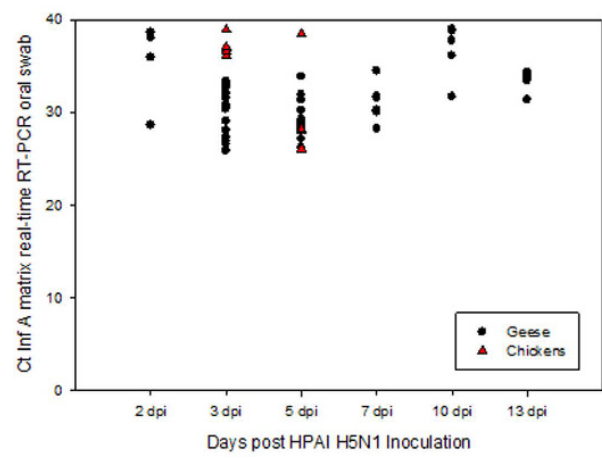

B

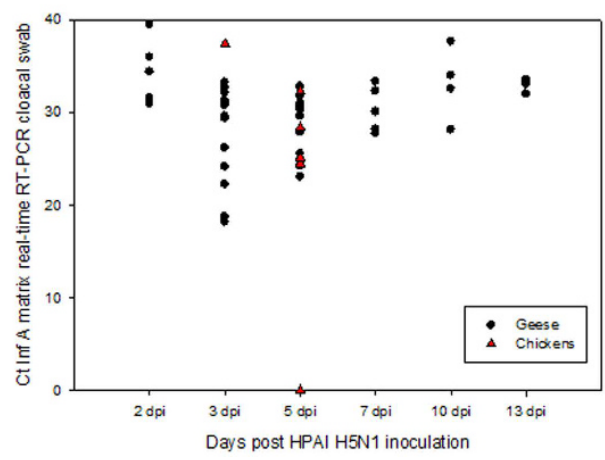

Figure 6. Virus shedding patterns of Chinese geese infected with 10,000 PFU of FAV-002/H5N1. Total RNA was extracted from oral (A) and cloacal (B) specimens and was tested using the avian influenza matrix based real time RT-PCR assay.

Oral and cloacal shedding. Virus shedding was assessed by influenza A virus matrix gene real-time RT-PCR assay on total RNA extracted from oropharyngeal and cloacal swab specimens. The shedding patterns of the infected ducks and contact chickens (Fig. 5) and geese and chickens (Fig. 6) were similar beginning as early as $2 \mathrm{dpi}$, reaching a peak by 3 to $5 \mathrm{dpi}$ and persisting for up to $13 \mathrm{dpi}$. The magnitude of shedding in oropharyngeal (Figs 5A and 6A) and cloacal swab samples (Figs 5B and 6B) was similar.

Serology. Chinese geese and Muscovy ducks that were infected with FAV-002/H5N1 virus began to develop influenza A virus nucleoprotein antibodies at $7 \mathrm{dpi}$ with cELISA percent inhibition values peaking by $13 \mathrm{dpi}$ (Fig. 7A). H5 antibodies were first detected at $13 \mathrm{dpi}$ and peaked at the termination of the experiment (Fig. 7B).

Microscopic lesions in birds. The histological lesions observed in geese, turkeys and ducks were similar with some variations described below. The lesions are illustrated in Fig. 8A-H. In all species there were areas of extensive pancreatic necrosis. This was associated with abundant viral antigen in geese and turkeys but smaller amounts of antigen in the ducks. Significant hepatic necrosis was observed in all species and varied from massive hepatic necrosis with associated extensive positive immunostaining in the geese, to multifocal lytic necrosis with heterophil infiltration in the turkeys. Splenic necrosis was observed in all species with varying severity and was associated with immunopositivity for viral antigen. Brain lesions were subtle and variable and included necrosis with gliosis as well as meningitis, ependymitis and inflammation of the choroid plexus. Extensive viral antigen was detected in the brain of the turkeys while moderate amounts were observed in the geese and ducks. Lesions observed in the cecal tonsil included hemorrhage, lymphoid depletion and inflammation. Table 2 summarizes the relationship between viral antigen load as determined by immunostaining and influenza A matrix gene copy number as determined indirectly by real-time RT-PCR assay for various tissues in inoculated and contact birds.

Pathobiological characteristics of FAV-002/H5N1 in mice and pigs. Mice. FAV-002/H5N1 was found to be highly virulent in mice with an $\mathrm{LD}_{50}$ of $46 \mathrm{PFU}$. In contrast, the A/American wigeon/BC/050-31/2015 ( $\mathrm{H} 5 \mathrm{~N} 8$ ) virus (designated $\mathrm{AW}-050 / \mathrm{H} 5 \mathrm{~N} 8$ ) was moderately pathogenic to mice with an $\mathrm{LD}_{50}$ of approximately 776 PFUs and the A/American green-winged teal/Washington/ 195750/2014 (H5N1) virus (designated AGT/H5N1) was mildly pathogenic with an $\mathrm{LD}_{50}>2.5 \times 10^{4}$ PUUs. Survival curves of FAV-002/H5N1, AGT/H5N1 and 
A

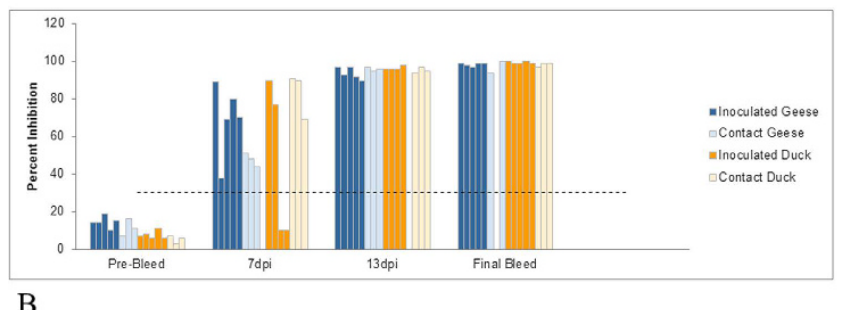

B

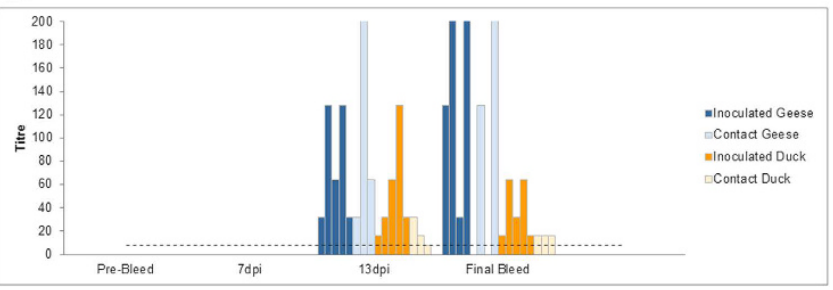

Figure 7. Serologic data for Chinese geese and Muscovy ducks that were infected with FAV-002/H5N1 virus and their corresponding contact groups. (A) shows influenza A virus nucleoprotein antibodies levels at different intervals of time using cELISA. Values above $30 \%$ inhibition (dotted line) were considered positive. No significant differences were found among inoculated versus contact ducks and geese at each time point. Significant differences ( $\mathrm{P}$ value $<0.001$ ) were however found between final bleed versus pre-bleed, $13 \mathrm{dpi}$ versus pre-bleed, $7 \mathrm{dpi}$ versus pre-bleed, final bleed versus $7 \mathrm{dpi}$ and $13 \mathrm{dpi}$ versus $7 \mathrm{dpi}$ groups based on twoway ANOVA followed by the Holm-Š́dák multiple comparison test. (B) illustrates anti-H5 antibody levels based at different intervals of time. Antibody detection is based on the hemagglutination-inhibition test using homologous FAV-002/H5N1 antigen. HI titers above 8 (dotted line) were considered positive. A statistically significant $(\mathrm{P}=0.023)$ interaction was found between animal groups (inoculated/contact geese and inoculated/ contact ducks) and time post-inoculation. Statistically significant differences were observed in HI titers of animals between the following time points: final bleed versus pre-bleed $(\mathrm{P}<0.001)$, final bleed versus $7 \mathrm{dpi}(\mathrm{P}<0.001)$, 13 dpi versus pre-bleed $(\mathrm{P}=0.027)$ and $13 \mathrm{dpi}$ versus $7 \mathrm{dpi}(\mathrm{P}=0.022)$. Inoculated geese showed significantly different $\mathrm{HI}$ titers at the following time points: final bleed versus pre-bleed $(\mathrm{P}<0.001)$, final bleed versus $7 \mathrm{dpi}$ $(\mathrm{P}<0.001)$ and final bleed versus $13 \mathrm{dpi}(\mathrm{P}=0.003)$. Finally significant differences in $\mathrm{HI}$ titers were observed in the contact geese group at the following time points: final bleed versus pre-bleed $(\mathrm{P}=0.011)$ and final bleed versus $7 \mathrm{dpi}$ $(\mathrm{P}=0.013)$. Analysis was by two-way ANOVA followed by the Holm-Š́dák multiple comparison test.

\begin{tabular}{|c|c|c|c|c|c|c|c|c|c|c|c|c|}
\hline \multirow[b]{3}{*}{ Tissue } & \multicolumn{6}{|c|}{ Geese Group } & \multicolumn{6}{|c|}{ Duck Group } \\
\hline & \multicolumn{2}{|c|}{$\begin{array}{l}\text { Inoculated goose } \\
5 \mathrm{dpi}\end{array}$} & \multicolumn{2}{|c|}{$\begin{array}{l}\text { Contact goose } \\
6 \mathrm{dpc}\end{array}$} & \multicolumn{2}{|c|}{$\begin{array}{c}\text { Contact chicken } \\
4 \text { dpc }\end{array}$} & \multicolumn{2}{|c|}{$\begin{array}{l}\text { Inoculated } \\
\text { duck } 5 \text { dpi }\end{array}$} & \multicolumn{2}{|c|}{$\begin{array}{c}\text { Contact duck } \\
8 \mathrm{dpc}\end{array}$} & \multicolumn{2}{|c|}{$\begin{array}{c}\text { Contact chicken } \\
8 \mathrm{dpc}\end{array}$} \\
\hline & 1Ct value & IHC & Ct value & IHC & Ct value & IHC & Ct value & IHC & Ct value & IHC & Ct value & IHC \\
\hline Brain & 22.47 & ++ & 21.44 & + & 19.97 & +++ & 27.54 & Neg & 30.48 & + & 20.51 & +++ \\
\hline Cecal tonsil & 23.14 & ++ & 20.55 & +++ & 20.00 & +++ & 31.62 & $\mathrm{Neg}$ & 29.92 & Neg & 22.19 & +++ \\
\hline Heart & 20.95 & ++ & 20.89 & ++ & 17.27 & ++++ & 34.34 & $\mathrm{Neg}$ & 32.29 & Neg & 16.49 & ++++ \\
\hline Jejunum & 20.97 & & 21.74 & ++ & 20.79 & ++ & 29.87 & + & 31.83 & Neg & 22.85 & ++ \\
\hline Kidney & 21.33 & +++ & 18.94 & +++ & 17.25 & ++ & 27.28 & + & 31.20 & Neg & 19.87 & ++ \\
\hline Liver & 16.19 & ++++ & 17.65 & ++++ & 21.27 & +++ & 30.57 & + & 33.46 & + & 23.30 & ++ \\
\hline Lung & 25.79 & ++++ & 21.25 & +++ & 24.34 & ++++ & 25.02 & + & 32.07 & + & 23.09 & ++++ \\
\hline Muscle & 23.87 & + & 23.60 & + & 21.48 & + & 29.65 & + & 28.71 & + & 19.56 & ++ \\
\hline Pancreas & 22.75 & & 20.54 & ++ & 23.75 & ++ & 25.65 & ++ & 35.27 & Neg & 28.80 & + \\
\hline Proventriculus & $\mathrm{NA}$ & ++ & 22.46 & +++ & 19.24 & +++ & 31.57 & $\mathrm{Neg}$ & 31.61 & Neg & 23.52 & +++ \\
\hline Spleen & 23.84 & ++++ & 21.19 & ++++ & NA & ++++ & 34.00 & + & 31.47 & + & 21.75 & ++++ \\
\hline Trachea & 24.01 & + & 22.66 & ++ & 20.53 & ++ & 22.83 & +++ & 28.76 & Neg & 23.34 & ++ \\
\hline
\end{tabular}

Table 2. Virus load as determined by IHC and RT-qPCR in tissues of inoculated and contact birds. ${ }^{1}$ Crossing threshold for influenza A virus matrix gene real-time RT-PCR assay. ${ }^{+}$mild immunostaining ( $<25 \%$ of the section); ${ }^{++}$moderate immunostaining ( $25 \%$ to $50 \%$ of the section); ${ }^{++}$abundant immunostaining ( $51 \%$ to $75 \%$ of the section); ${ }^{++++}$intense immunostaining ( $>75 \%$ of the section). Neg - negative for immunostaining; NA - not available; dpi - days post-inoculation; dpc - days post-contact.

AW-050/H5N8 inoculated mice are shown in Fig. 9A-C respectively. Weight loss was dose dependent in the FAV002/H5N1 (Fig. 9D), AGT/H5N1 (Fig. 9E) and AW-050/H5N8 (Fig. 9F) groups. Mice inoculated with $10^{4}$ PFUs of AW-050/H5N8 exhibited a significant weight loss of approximately $25 \%$ body weight by $6 \mathrm{dpi}$, in contrast to 

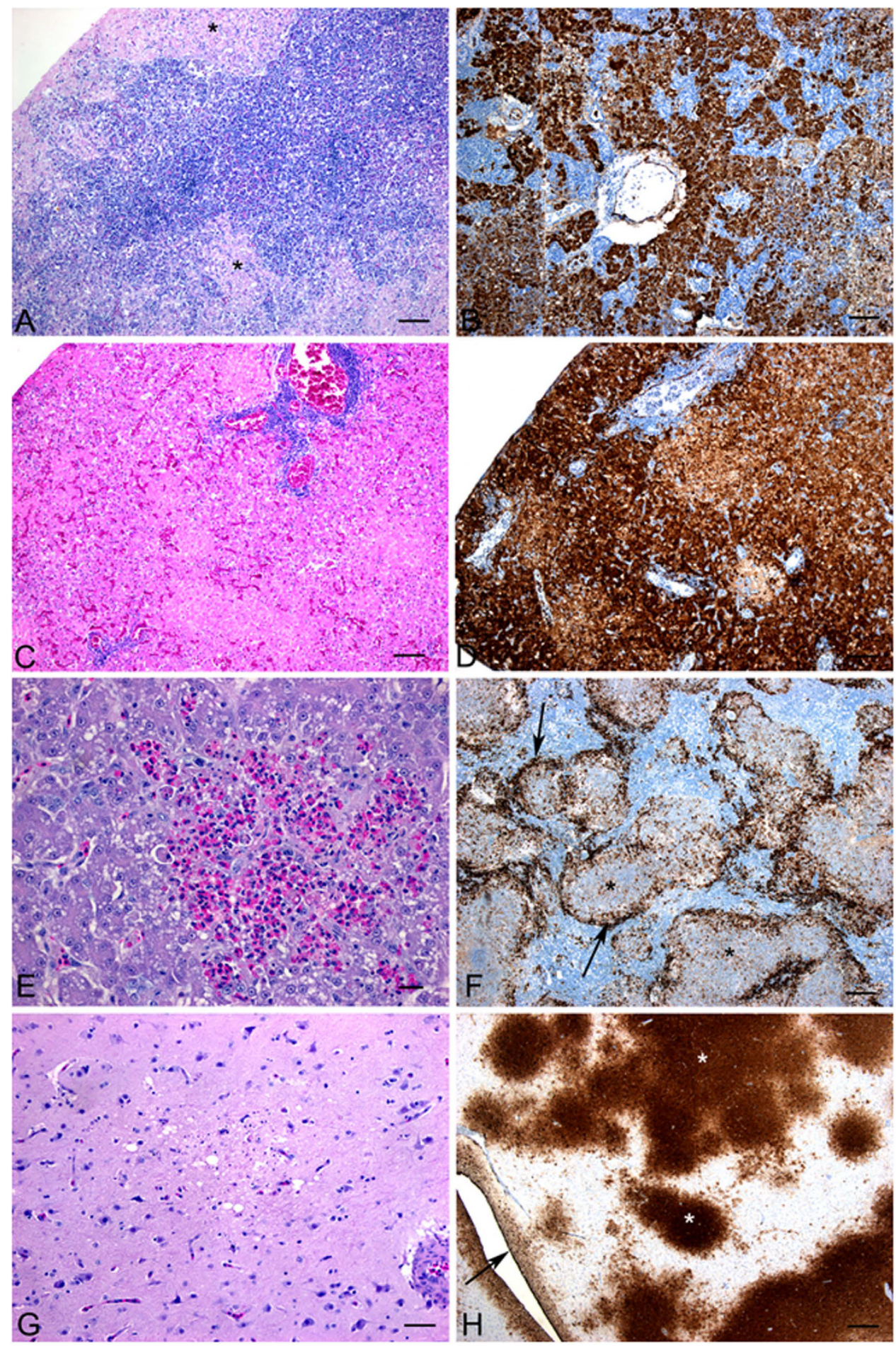

Figure 8. Microscopic lesions observed in geese, turkeys and ducks that were infected with FAV-002/ H5N1. (A) Extensive necrosis in the pancreas of a Chinese goose. (B) Presence of abundant viral antigen in the pancreas of a Chinese goose. (C) Presence of large areas hepatic necrosis with heterophil infiltration in a turkey. (D) Extensive area of hepatic necrosis associated with positive immuno-staining (arrow) in a goose. (E) Large multifocal areas of necrosis in the spleen of a turkey. (F) Positive immuno-staining in the multifocal areas of necrosis in the spleen of a Chinese goose. (G) Brain lesions in Muscovy ducks were subtle and variable and included necrosis with gliosis and meningitis, ependymitis and inflammation of the choroid plexus. (H) Extensive viral antigen $\left.{ }^{*}\right)$ in the brain of the turkey.

the mice in the group that received lower amounts of virus which exhibited $<10 \%$ weight loss at $3-7 \mathrm{dpi}$ (Fig. 9F). To determine the pathogenicity of FAV- $002 / \mathrm{H} 5 \mathrm{~N} 1$, five mice were infected with $10^{2} \mathrm{PFU}$ of virus and sacrificed 
A

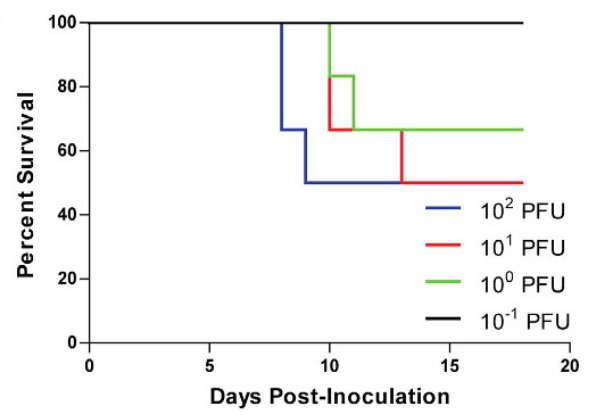

B

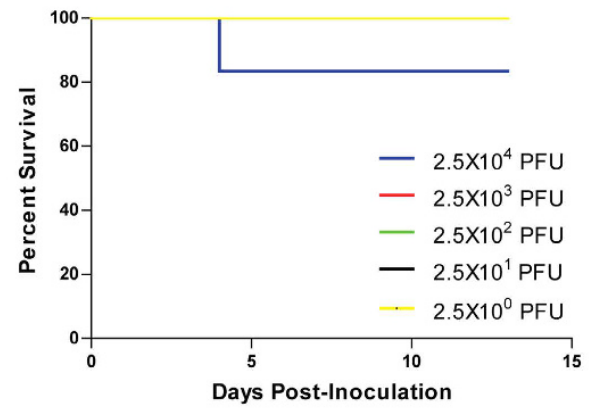

C

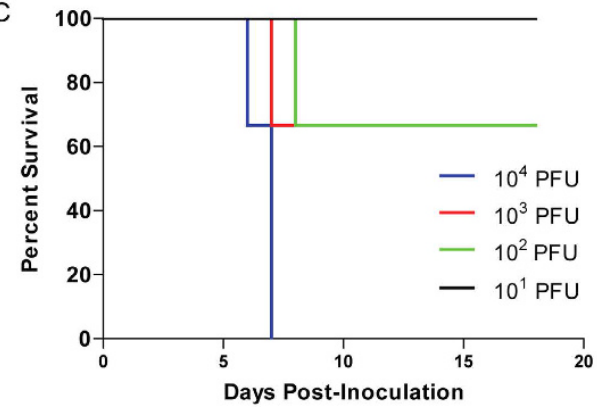

D
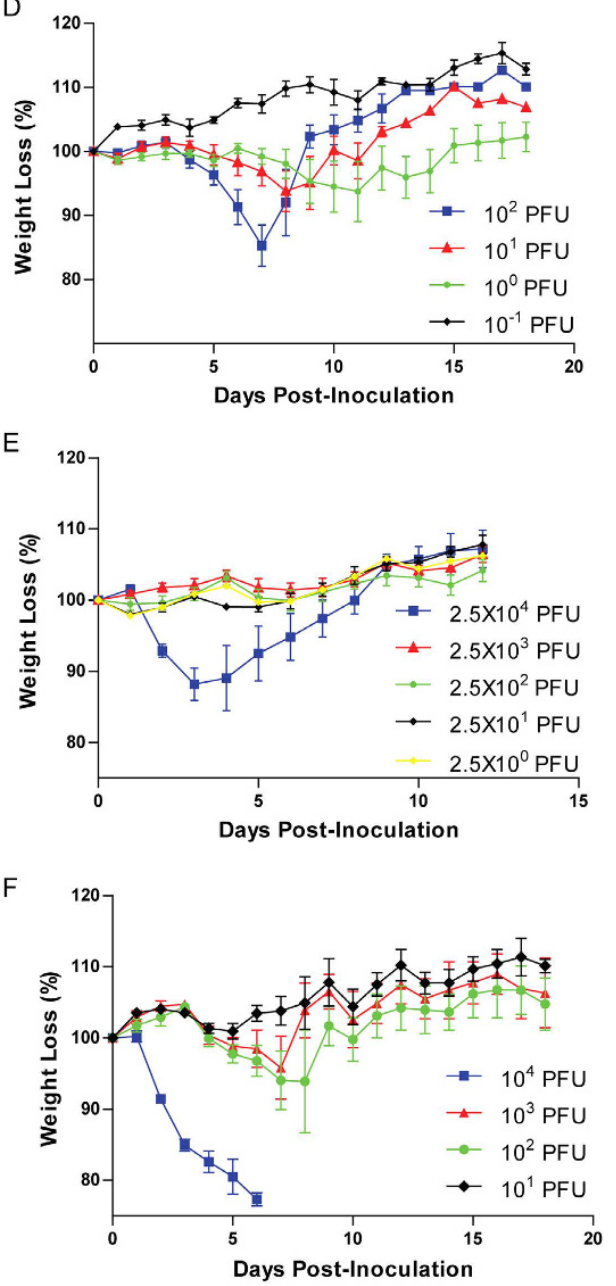

Figure 9. Survival and weight loss of mice infected with H5N1 and H5N8 viruses. Six- to 7-week-old female $\mathrm{Balb} / \mathrm{c}$ mice were intranasally challenged with 10 fold serial dilutions of FAV-002/H5N1 (A,D), AGT/H5N1 (B,E) and AW-050/H5N8 (C,F) and observed for survival and weight loss. The percent survival was determined and mouse $50 \%$ lethal dose (MLD50) was calculated by the Miller and Tainter method (43). $\mathrm{N}=6$ mice per group.

at 3 and $6 \mathrm{dpi}$, and lungs, heart, gut, kidney and spleen were harvested for RNA extraction. Viral RNA was found in the lungs of the mice at 3 and $6 \mathrm{dpi}$, having $\log _{10}$ values of 4.0 and 5.7 copies/gram of tissue respectively. In addition, low copies of viral RNA $\left(3.66 \times 10^{1}\right.$ and $7.11 \times 10^{1}$ copies/gram of tissue) were detected in the kidney and heart of only one mouse at $6 \mathrm{dpi}$. Viral RNA was not detected in the gut or spleen of any of the other animals.

Histologic lesions in mouse lungs were mild at $3 \mathrm{dpi}$ and characterized by necrosis and inflammation in occasional bronchioles and a few small foci of necrotizing interstitial pneumonia (Fig. 10A). At 6 dpi, the lesions were similar, but were more extensive involving up to $30 \%$ of the examined lung section (Fig. 10B) with the addition of vasculitis. Influenza A viral antigen could be detected in bronchiolar epithelial cells at both time points (Fig. 10C). At 6 dpi detection of viral antigen was frequently detected in interstitial cells which appeared morphologically to be macrophages (Fig. 10D).

Pigs. No clinical signs were observed in any of the pigs following intranasal inoculation with FAV-002/H5N1. No detectable levels of influenza A virus RNA (Ct values $<35$ ) were found by real-time RT-PCR in all oral and nasal swabs collected at different time points with the exception of one nasal swab collected from a single pig at $1 \mathrm{dpi}$. Histologic lesions were observed in some of the lung tissues at both 3 and $5 \mathrm{dpi}$ and were characterized by expansion of alveolar walls due to inflammatory cell infiltration, mild edema and increase in numbers of alveolar macrophages consistent with mild to moderate interstitial pneumonia (Fig. 11). Bronchiolar changes were mild consisting of some disorganization and degeneration of epithelial cells (Fig. 11A). In addition, in some areas there was perivascular and peribronchiolar cuffing of mononuclear inflammatory cells. Limited influenza viral antigen was detected in occasional bronchiolar epithelial cells (Fig. 11B) as well as rare cells within alveolar walls morphologically consistent with macrophages. Positive immunostaining was also observed in rare tracheal epithelial cells. 


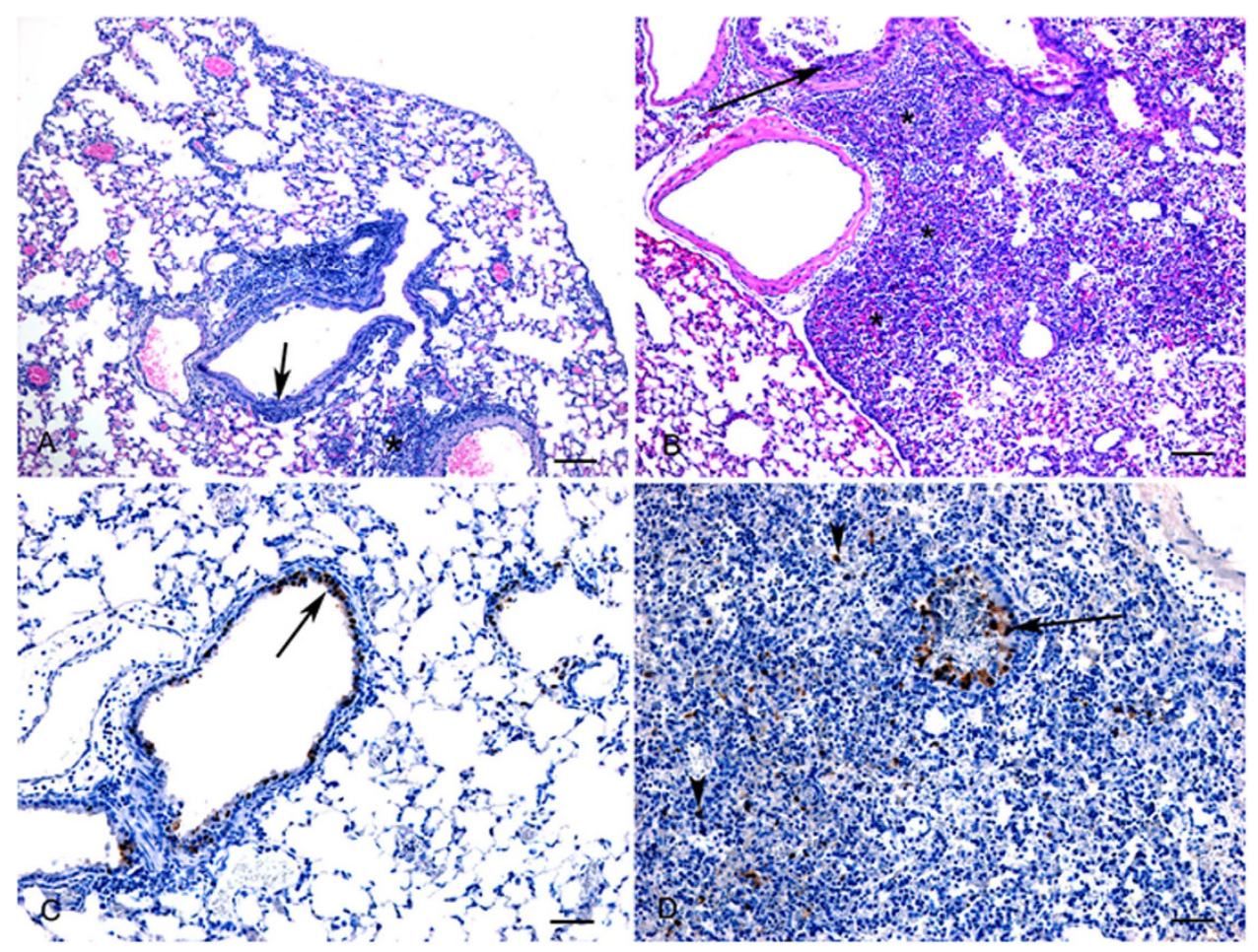

Figure 10. Histopathology (HE) and immunohistochemistry (IHC) findings in lungs from H5N1 infected mice. (A) Day 3: Mild to moderate bronchiolitis (arrow) and scattered foci of interstitial pneumonia $\left({ }^{*}\right)$. HE, bar $=100 \mu \mathrm{m}$. (B) Day 6: Large areas of necrotizing interstitial pneumonia $\left(^{*}\right)$ and bronchiolitis (arrow). HE, bar $=100 \mu \mathrm{m}$. (C) Day 3: Positive immunostaining for influenza A antigen is primarily observed in bronchiolar epithelial cells (arrow). IHC, bar $=50 \mu \mathrm{m}$. (D) Day 6: Viral antigen is detected in bronchiolar epithelial cells (arrows) as well as in macrophages (arrowheads). IHC, bar $=50 \mu \mathrm{m}$.

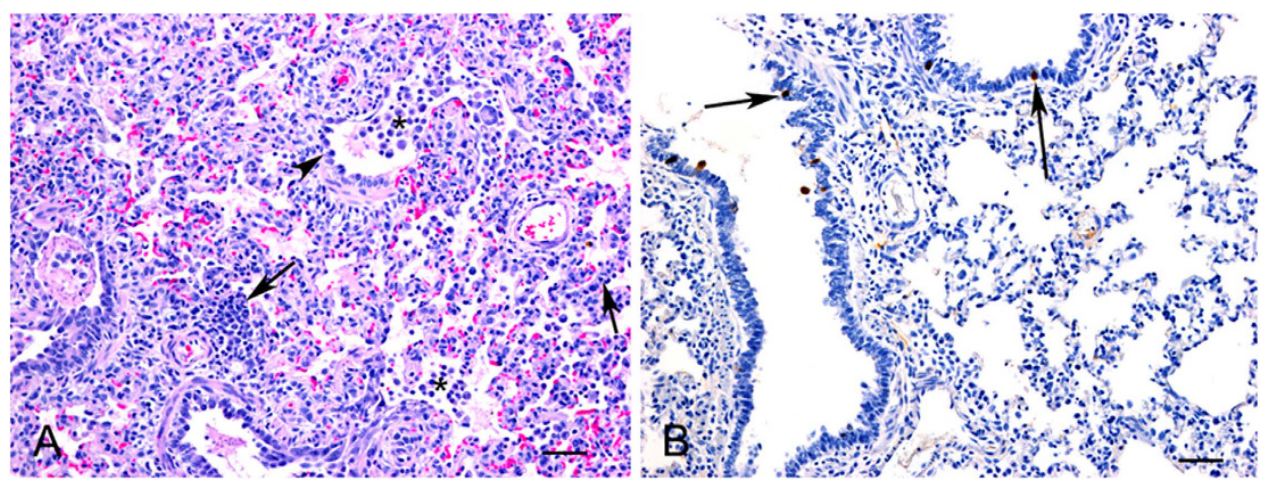

Figure 11. Histopathology (HE) and immunohistochemistry (IHC) findings in lungs from FAV-002/

H5N1 infected pigs. (A) Microscopic lesions in a lung characterized by interstitial infiltration of inflammatory cells (arrows), mild bronchiolar changes with degeneration and disorganization of epithelial cells (arrowhead) and increased numbers of macrophages in bronchiolar lumens and alveoli. HE, bar $=50 \mu \mathrm{m}$. (B) Positive immunostaining for influenza A viral antigen was detected in scattered bronchiolar epithelial cells. IHC, $\mathrm{bar}=50 \mu \mathrm{m}$.

The two pigs that did not undergo timed postmortem examinations did develop influenza A virus nucleoprotein antibodies as determined by cELISA.

Neuraminidase Enzyme Kinetics. Since the major difference between FAV-002/H5N1 and AGT/H5N1 was the length of the NA gene, it was important to determine whether the viruses exhibit any difference in NA activity. Comparison of the NA activities of FAV-002/H5N1 and AGT/H5N1 demonstrated that the Km value was not significantly different between the two viruses $(\mathrm{Km} \mathrm{FAV}-002 / \mathrm{H} 5 \mathrm{~N} 1=230.8 \pm 25.21$ and AGT/H5N1 $186.9 \pm 24.37)$. However, there was more than a three-fold increase in the $\mathrm{V}_{\max }$ of FAV-002/H5N1 $\left(\mathrm{V}_{\max }=10.68\right.$ 
A

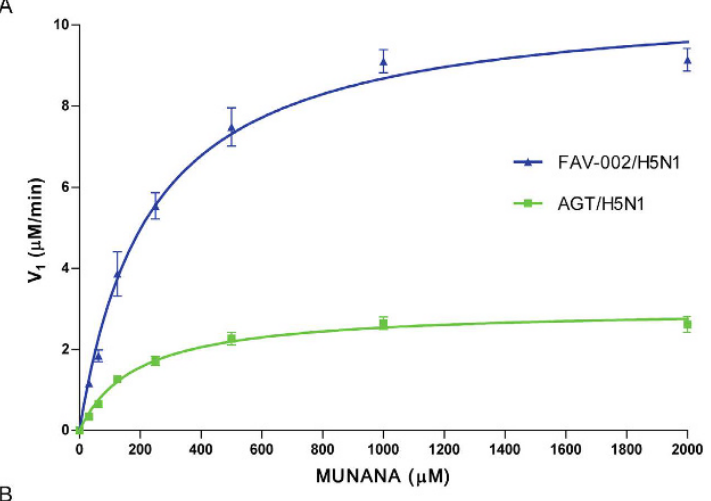

B

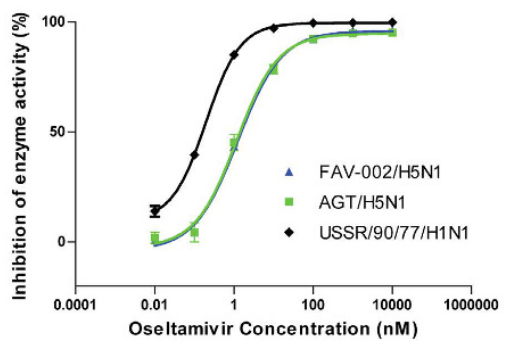

Figure 12. Neuraminidase enzyme kinetics and sensitivity of H5N1 viruses to oseltamivir. (A) Neuraminidase kinetic curves for FAV-002/H5N1 and AGT/H5N1. Relative fluorescent unit (RFU) values for each virus (FAV-002/ $\mathrm{H} 5 \mathrm{~N} 1$ and AGT/H5N1) were plotted against a 2-fold dilution series of MUNANA to determine the maximum velocity (Vmax) and the binding affinity $(\mathrm{Km})$ to MUNANA for each virus. (B) Comparative sensitivity to oseltamivir for each virus is reflected by the percent inhibition of enzyme activity at each concentration of oseltamivir carboxylate, plotted as the ratio of RFU at each dose over the RFU value with no drug treatment. P value $<0.0001$.

relative fluorescent units/sec \pm 0.3638 ; $\mathrm{p}$ value $<0.0001)$ compared to $\mathrm{AGT} / \mathrm{H} 5 \mathrm{~N} 1\left(\mathrm{~V}_{\max }=3.01\right.$ relative fluorescent units/sec $\pm 0.1160 ; \mathrm{p}$ value $<0.0001)$. NA enzyme kinetic results are illustrated in Fig. $12 \mathrm{~A}$.

Oseltamivir Sensitivity. FAV-002/H5N1 and AGT/H5N1 are both susceptible to oseltamivir with $\mathrm{IC}_{50}$ concentrations of 1.259 (range 0.8421-1.868) and 1.170 (range 0.8549-1.601) nM respectively. A/USSR/90/1977 (H1N1) was used as a control and had an $\mathrm{IC}_{50}$ of 0.1986 (range 0.1725 and 0.2287 ) nM. Results of this experiment are summarized graphically in Fig. 12B.

\section{Discussion}

The unprecedented transcontinental movement of Eurasian H5N8 virus to the west coast of North America was the priming event that led to the creation of two novel reassortant $\mathrm{H} 5 \mathrm{~N} 1$ and $\mathrm{H} 5 \mathrm{~N} 2$ viruses. The North American gene segments that comprise the reassortant $\mathrm{H} 5 \mathrm{~N} 1$ and $\mathrm{H} 5 \mathrm{~N} 2$ viruses appear to have originated from different wild bird origin progenitor viruses. According to the APHIS website (http://www.aphis.usda.gov), three novel reassortant $\mathrm{H} 5 \mathrm{~N} 1$ viruses including AGT/H5N1 were isolated in Whatcom County, Washington; two from American wigeons and one from an American green winged teal. The novel reassortant FAV-002/H5N1 described in the current study was isolated from a backyard chicken flock in the Fraser Valley of British Columbia. FAV$002 / \mathrm{H} 5 \mathrm{~N} 1$ was almost identical to the isolate from the US AGT/H5N1 except for a 19 amino acid deletion in the stalk of the neuraminidase in addition to a number of other minor changes involving other gene segments. NA stalk deletions have been associated with the adaption of virus from natural waterfowl reservoir hosts to gallinaceous species as well as with broader host range and virulence ${ }^{22}$. We were not able to detect the presence of untruncated NA similar to that seen in AGT/H5N1 from the backyard flock where FAV-002/H5N1 was isolated. This might indicate that the deletion occurred at the very early stages of infection before sampling was conducted, or the truncation may have already existed in the viral population before it was introduced to the backyard flock. Previous studies ${ }^{23,24}$ have demonstrated that NA stalk deletions are often accompanied by the addition of glycosylation sites in the HA protein which is thought to be necessary to maintain a functional balance between the HA and NA, the latter being an essential requirement for infectivity. Notably, no corresponding changes were found in the HA of FAV-002/H5N1. The NA stalk deletion found in FAV-002/H5N1versus AGT/H5N1 was associated with a more than three-fold increase in Vmax but no significant change in substrate affinity. This is in contrast to the decreased NA activity of influenza A viruses with truncated NA stalks that has been reported by others ${ }^{25-27}$. This decrease in NA activity, expressed as diminished ability of the virus to elute from red blood cells, is thought to be due to the NA not being able to access its sialic acid substrate properly, possibly because the enzyme active site is located too close to the viral envelope. Obviously the functional balance between HA and NA is complex and any advantage provided by NA stalk deletions may be dependent on several factors including the host and 
specific HA-NA pairings. Noteworthy is the fact that all Gs/Gd-lineage H5N1 viruses that spread from Asia to other regions possessed NA stalk deletions that were similar to the one found in FAV-002/H5N128.

Since the emergence of the Gs/Gd-like H5N1 viruses in 1996, the length of the neuraminidase stalk region has varied considerably among different strains and this is thought to be associated with virulence in some animal hosts $^{29}$. According to Matsuka et al. ${ }^{29}$, Eurasian H5N1 viruses with a truncated NA stalk possessed an increased virulence for mice but not chickens when compared with viruses with an untruncated stalk. Viruses with NA stalk deletions were 10,000-fold more pathogenic than their counterpart H5N1 viruses with no deletion. In the current study, the mouse $\mathrm{LD}_{50}$ value for the novel FAV-002/H5N1 virus was low (46 PFU) and the value was almost identical to pathogenic strains of Gs/Gd-like HPAI H5N1 viruses indicating some similarity in terms of virulence in mice. In contrast, the $\mathrm{LD}_{50} \mathrm{~s}$ of the AGT/H5N1 virus without a truncated NA stalk, and the AW-050/H5N8 virus were both significantly higher. These results are consistent with previous findings that $\mathrm{H} 5 \mathrm{~N} 1$ viruses with truncated NA stalks are more virulent for mice and that clade 2.3.4.4 H5N8 viruses produce mild clinical disease in experimentally infected mice, dogs and ferrets ${ }^{6,21}$.

The PB1-F2 of FAV-002/H5N1 encodes for a protein of 90 AA and has serine at position 66 that was previously demonstrated to impact virulence in Eurasian HPAI H5N1 viruses by inhibiting interferon induction through binding of the PB1-F2 to the MAVS adaptor protein ${ }^{30}$. In addition, the PB1-F2 has some additional molecular signatures $(62 \mathrm{~L}, 75 \mathrm{R}, 79 \mathrm{R}$, and $82 \mathrm{~L})$ that are known to contribute in the cytokine release and inflammatory responses ${ }^{30}$. None of the remaining mutations were found to be associated with pathogenicity based on inventory of amino acid mutations in $\mathrm{H} 5 \mathrm{~N} 1$ viruses used by the influenza surveillance and research community as a tool to inform the influenza knowledge base for surveillance and public health preparedness. http://www.cdc.gov/flu/ pdf/avianflu/h5n1-inventory.pdf.

Hemagglutinin protein sequences of the novel FAV-002/H5N1, AGT/H5N1 and AW-050/H5N8 were identical at their respective receptor binding sites. Consequently, FAV-002/H5N1 should have similar binding preference for avian $\alpha 2-3$ receptors and to a lesser extent $\alpha 2-6$ receptors indicating inadequate zoonotic potential. Despite this it should be noted that recent human infections involving clade 2.3.4.4 H5N6 viruses in China have resulted in severe respiratory disease and even death ${ }^{31,32}$. During the mammalian animal trials, pigs that were infected with FAV-002/H5N1 were sub-clinically affected but did seroconvert. Virus shedding was very minimal and microscopically the lesions were restricted to the lungs and were very mild with only a small number of lung cells positive for influenza A virus antigen as determined by IHC. Previous experimental studies in pigs using various Gs/Gd-like H5N1 HPAI viruses resulted in either no virological or serological confirmation of infection or mild to moderate infection that was restricted to the respiratory tract ${ }^{33,34}$.

Experimental studies in mice with Gs/Gd-like HPAI H5N1 have demonstrated that viruses which exhibited high virulence in mice replicated in the lungs and other organs without prior adaptation, while viruses of low virulence were restricted to the respiratory tract ${ }^{21,27,29}$. In the current study, FAV-002/H5N1 was able to replicate in the lungs of mice causing necrotizing interstitial pneumonia and vasculitis. Presence of viral antigen in the lungs was also confirmed by IHC and by real-time RT-PCR; however, despite the highly pathogenic nature of the FAV-002/H5N1, only minimal levels of viral nucleic acid were detected in the heart and kidneys of one mouse at $6 \mathrm{dpi}$. This lack of dissemination may be due in part to the absence of E627K and D701N mutations in PB2 which are associated with higher polymerase activity and improved viral replication in mammalian cells as well as enhanced virulence in mice ${ }^{35}$.

Historically, influenza A viruses of all existing HA and NA subtypes have been isolated from different Anseriformes and Charadriiformes genera and species and are not normally associated with clinical disease or mortality. This changed after the emergence of Gs/Gd-like H5N1 viruses in 1996 as various strains were capable of killing different species of ducks, geese and shorebirds ${ }^{36,37}$. Similar to Gs/Gd-like H5N1 viruses that were found to be highly pathogenic to waterfowl, FAV-002/H5N1 was also pathogenic in experimentally infected Chinese geese (Anser cynoides domesticus) and Muscovy ducks (Cairnia moschata foma domestica) and was able to replicate systemically in both species. The virus was shed cloacally and orally and transmitted to and caused mortality in naïve contact chickens, ducks and geese. To date there is no information that FAV-002/H5N1, and its closest ancestor AGT/H5N1 that was isolated from hunter killed green-winged teal (Anas crecca), have been associated with any die-offs or clinical disease in wild waterfowl. So far this novel reassortant virus has only been detected in the lower Fraser Valley of British Columbia and in Whatcom County, Washington. Both are located within the Pacific flyway and there is no evidence of spread to other flyways. Furthermore, there is no indication thus far that this virus has been associated with any additional outbreaks in gallinaceous species.

\section{Methods}

Case Report. In February 2015, a backyard chicken layer flock consisting of 100 birds near Chilliwack, British Columbia experienced a sudden increase in mortality. Swab and tissue specimens collected from this flock were submitted to the provincial veterinary diagnostic laboratory (Abbotsford, BC). The samples tested positive using modified versions of the Spackman et al. ${ }^{38}$ influenza A matrix gene and H5 hemagglutinin gene real-time RT-PCR assays and were sent to the National Center for Foreign Animal Disease Laboratory (NCFAD) in Winnipeg, Manitoba for confirmation. Twelve tissue specimens collected in parallel by a Canadian Food Inspection Agency (CFIA) team were also sent to NCFAD for analysis.

Viruses. A/chicken/BC/FAV-002/2015 (H5N1) (hereafter designated FAV-002/H5N1) was isolated from a backyard layer chicken flock near Chilliwack, British Columbia. The full genome sequence of FAV-002/H5N1 has been deposited in the NCBI data base with accession numbers KP892988 to KP892995. A/American wigeon/ BC/050-31/2015 (H5N8) (hereafter designated as AW-050/H5N8) was isolated from a hunter killed American wigeon in our laboratory. The virus was isolated in embryonating specific pathogen free (SPF) chicken eggs and the virus sequences are deposited in GISAID website under accession number EPI_ISL_178249. A/American 
green-winged teal/Washington/ 195750/2014 (H5N1) (hereafter designated as AGT/H5N1) was kindly provided to us by Dr M.K. Torchetti (Diagnostic Virology Laboratory, National Veterinary Services Laboratories, Ames, Iowa). The sequence of this virus is available at NCBI data base under accession numbers KP739418 to KP739425.

Virus isolation and characterization. Swab and tissue specimens that screened positive on AIV matrix and $\mathrm{H} 5$ real-time RT-PCR assays were used for virus isolation by inoculating the allantoic cavity of 9-day-old SPF embryonated chicken eggs (ECE). The presence of virus in the allantoic fluids harvested from dead embryos was confirmed by hemagglutination assay and the agent was typed by hemagglutination-inhibition assay using standard methods (http://www.oie.int/fileadmin/Home/eng/Health_standards/tahm/2.03.04_AI.pdf_AI.pdf). In addition, total RNA was extracted from allantoic fluids and the presence of AIV confirmed by influenza A matrix and H5 based real-time RT-PCR assays.

Virus genome sequencing. Sanger Sequencing. Total RNA was extracted directly from field specimens and from allantoic fluids using the MagMax ${ }^{\text {TM }}$ - 96 AI/ND Viral Extraction Kit (Ambion) and MagMax Express robotic system according to the manufacturer's recommendations (Life Technologies). The eight influenza A viral gene segments were amplified in one step RT-PCR using a universal primer set ${ }^{39}$ and the qScript XLT One-Step RT-PCR Kit (Quanta Biosciences). The amplified RT-PCR products were resolved by agarose gel electrophoresis, cut from the gel and purified using a QIAquick gel extraction kit (Qiagen). The purified RT-PCR amplicons were then ligated into pCR4-Topo (Life Technologies) and used to transform OneShot competent $E$. coli. The resulting plasmids were sequenced using BigDye Terminator chemistry version 3.1 (Life Technologies) and an Applied Biosystems 3130xl Genetic Analyzer.

Sequencing using Ion Torrent. Full-length influenza A virus gene segments were amplified directly from total RNA that was extracted from $10 \%(\mathrm{w} / \mathrm{v})$ homogenates made from clean (brain, lungs, spleen and heart) and dirty (gut and its contents) tissue pools following the protocol described by Hoffman et al. $^{39}$. In addition, the NA genes were amplified from RNA extracted from all swab and tissue specimens collected from different chickens. The RT-PCR products were purified as described above. Purified gene segments were subsequently quantified using a Biodrop Touch UV spectrophotometer. Equimolar pools of all gene segments were generated when performing whole genome sequencing. Library construction was performed using the Ion Xpress ${ }^{\mathrm{TM}}$ Plus Fragment Library Kit (Life Technologies) utilizing a 5 minute shearing time. IonXpress ${ }^{\text {TM }}$ Barcode adapters (Life Technologies) were applied to each full genome isolate or individual gene segments when required. Size selection of each barcoded library was performed on a PIPPIN-Prep using 2\% agarose gels (Sage Science). Size-selected libraries were qualitatively assessed using the Agilent High Sensitivity DNA Kit and Agilent 2100 Bioanalyzer. qPCR was performed with a 7500 Fast Real-Time PCR System (Applied Biosystems) and the Ion Library Quantitation Kit (Life Technologies) to determine template dilution factor for emulsion PCR. Barcoded libraries were pooled and DNA template was prepared for sequencing using the Ion PGM ${ }^{\mathrm{TM}}$ Template OT2 Reactions 200 kit (Life Technologies) with the Ion OneTouch ${ }^{\mathrm{TM}} 2$ System with ES for ISP enrichment. Quality control of Ion Sphere Particles (ISP) was performed using Ion Sphere ${ }^{\text {TM }}$ Quality Control Kit and a Qubit fluorometer (Life Technologies). Sequencing was performed with an Ion Torrent PGM ${ }^{\mathrm{TM}}$ instrument using an Ion $314^{\mathrm{TM}}$ Chip Kit v2 (Life Technologies) and an Ion $\mathrm{PGM}^{\mathrm{TM}} \mathrm{Hi}-\mathrm{Q}^{\mathrm{TM}}$ Sequencing Kit. Data analysis was performed using DNAstar SeqMan NGen ${ }^{\circledR}$ software, DNAstar Core suite and BLAST server at NCBI. During library build, Agencourt AMPure XP Reagent (Beckman Coulter, Inc.), was used for purification when required following all manufacturer protocols.

Phylogenetic analysis. Viral gene sequences were aligned with other sequences available on public databases (NCBI and GIAID data bases) using ClustalW and evolutionary history was inferred by using the Maximum Likelihood method based on the Tamura-Nei model ${ }^{40}$. The number of bootstrap replications was set to 1000 , and major tree branches were labeled with bootstrap values $>75 \%$. The analysis was performed using MEGA version 6 software ${ }^{41}$.

Animal Experiments. All experiments on live vertebrates were carried out in accordance with guidelines set out by the Canadian Council on Animal Care and all experimental manipulations carried out on live animals were approved by the Canadian Science Centre for Human \& Animal Health Animal Care Committee.

Chinese Geese and Muscovy ducks: Twenty Chinese geese (Anser cynoides domesticus) were purchased from a local supplier in Manitoba and 20 Muscovy ducks (Cairnia moschata foma domestica) were purchased from a private farm in Ontario. The geese and ducks were transported to the National Centre for Foreign Animal Disease (NCFAD) and were housed in biosafety level 3 plus (BSL-3+) animal cubicles. The geese were provided ad-libitum water and fed with Goose Grower from Master-feeds grain. Dried corn was given as supplement. The birds were floor housed and had access to a wading pool and filled water troughs.

Chickens and turkeys: Twenty 4- to 6-week-old Leghorn chickens (Gallus gallus domesticus) were acquired from the CFIA SPF flock in Nepean, Ottawa. Twenty 8- to 10-week-old AIV free turkey (Melleagris gallopavo) pullets were purchased from a local supplier in Manitoba. The chickens and turkeys were placed in BSL-3+ animal cubicles. The chickens and turkeys were fed with $20 \%$ Chick Starter feed from Masterfeeds and water provided ad libitum. Heat lamps provided as source of supplemental heat. Perches were provided as environmental enrichment. 
Intravenous pathogenicity index (IVPI). For this purpose, ten 4- to 6-week-old SPF Leghorn chickens were inoculated intravenously with $0.1 \mathrm{ml}$ of 1:10 dilution of sterile allantoic fluid containing FAV-002/H5N1. Ten control chickens were mock inoculated with the PBS diluent. Scores were collected according to procedures described in the OIE Manual of Diagnostic Tests and Vaccines for Terrestrial Animals (http://www.oie.int/ international-standard-setting/terrestrial-manual/access-online/).

Mean chicken lethal dose $\left(C_{L} D_{50}\right)$. Six-week-old SPF Leghorn chickens were placed in 4 different animal cubicles. Three groups of five chickens were inoculated intranasally with different dilutions of FAV-002/H5N1. The $4^{\text {th }}$ group was mock inoculated with PBS. The birds were observed daily for clinical signs and mortality over a period of 2 weeks.

Pathogenesis studies in different species of birds. Ducks and Geese. After a week of acclimatization, 15 Chinese geese and 15 Muscovy ducks, each housed in separate animal cubicles, were inoculated with $10^{4} \mathrm{PFU}$ of FAV-002/H5N1 by oronasal and cloacal routes. Twenty-four hrs following inoculation, 5 naive Chinese geese and 5 naïve Muscovy ducks were placed amongst the corresponding groups to commingle and assess virus transmission. In addition, 5 naïve chickens housed in wire dog kennels were placed in each corner of the animal cubicle with infected Chinese geese and Muscovy ducks. The cages housing the chickens were placed so that a portion of each cage had contact with the standing water in the animal cubicle. Swabs were collected from all birds on 2, $3,5,7,9,14$ and 20 days after infection or contact.

Turkeys. After a week of acclimatization, 10 turkeys were inoculated intranasally with $10^{3}$ PFUs of FAV-002/ H5N1. Twenty-four hrs following inoculation, 5 naïve contact turkeys were allowed to commingle amongst the infected turkeys to assess virus transmission. Swabs were collected on 2, 3 and $5 \mathrm{dpi}$.

Pathogenesis studies in mammals. Pigs. Four- to six-week-old Duroc piglets were obtained from a local supplier in Manitoba and housed in the BSL-3+ animal cubicles at NCFAD. The piglets were acclimatized for 1 week and blood and nasal swabs collected prior to virus inoculation. Piglets tested negative for influenza A virus nucleoprotein antibodies as determined by cELISA ${ }^{42}$ and for influenza A virus RNA as determined by real-time RT-PCR (31). Seven piglets were challenged by intranasal administration of $10^{6} 50 \%$ tissue culture infectious doses $\left(\mathrm{TCID}_{50}\right.$ ) of $\mathrm{H} 5 \mathrm{~N} 1$ in a $1 \mathrm{ml}$ volume. Sera were collected from the piglets prior to infection as well as 14 and 21 days following infection. Oral and nasal swabs were taken prior to inoculation and every day for six days post-inoculation (dpi) and one piglet was euthanized on day 3, 4, 5, and 6 post- inoculation. Lungs specimens including the apical, cardiac and caudal lobes were collected; half of the specimens were fixed in $10 \%$ formalin and the other half were frozen at $-70^{\circ} \mathrm{C}$.

Mice. Female Balb/c mice, 6-7 weeks old (Charles River Laboratories, QC) were used for all experiments. To determine the mouse $\mathrm{LD}_{50}\left(\mathrm{MLD}_{50}\right)$, groups of six mice were inoculated with $50 \mu \mathrm{l}$ of virus per mouse intranasally with 10 -fold dilutions of FAV-002/H5N1, AGT/H5N1 and AW-050/H5N8 viruses. MLD ${ }_{50}$ was calculated by the Miller and Tainter method ${ }^{43}$. To determine the pathogenicity of the virus five mice were infected with $10^{2} \mathrm{PFU}$ of virus and sacrificed at 3 and 6 days post infection. Lungs, heart, gut, kidney and spleen were harvested for RNA detection using RNAlater (Qiagen, ON, Canada) to preserve the RNA, followed by RNA extraction using the RNeasy Plus Mini kit (Qiagen). qRT-PCR was performed using the Lightcycler 480 RNA Master Hydrolysis Probe kit (Roche, ON, Canada) along with primers and probes targeting the matrix protein of influenza ${ }^{38}$. RNA was quantified by comparison to a standard curve based on known concentrations of plasmid (pPol vector) containing the $\mathrm{H} 5 \mathrm{~N} 1$ virus matrix gene.

Real-time RT-PCR assay. The presence of influenza A virus in swabs and tissues collected from animals was carried out using a semi quantitative real-time RT-PCR (RRT-PCR) assay described by Spackman et al. ${ }^{38}$. Full length, in vitro transcribed segment 7 RNA, serially diluted in RNase free water was run with each assay in order to give a semi-quantitative estimate of the viral load in each sample.

Neuraminidase Enzyme Kinetics. Virus titres were determined by plaque assay on MDCK cells (ATCC, VA, USA). Following adsorption of virus in 10 -fold serial dilutions, cells were overlayed with a $1 \%$ SeaPlaque ${ }^{\circledR}$ Agarose (Lonza, ME, USA) mixture containing minimal essential medium (MEM) and $1 \mu \mathrm{g} / \mathrm{ml}$ TPCK-trypsin. For the enzymatic assay, the substrate $2^{\prime}$-(4-Methylumbelliferyl)-a-D-N-acetylneuraminic acid (MUNANA; Sigma, ON, Canada) was diluted in a 2 -fold series $(2000 \mu \mathrm{M}$ to $0 \mu \mathrm{M})$ and $10 \mu \mathrm{l}$ was added into 96 well white round bottom plates (Grenier Bio-One, NC, USA). Virus was adjusted to $10^{5} \mathrm{PFU} / \mathrm{ml}$ and $10 \mu$ ladded to each well. The plate was read in a Synergy HTX plate reader (BioTek, VT, USA) pre-warmed to $37^{\circ} \mathrm{C}$. Fluorescence was captured every 90 seconds at $37^{\circ} \mathrm{C}$ for 60 minutes using excitation at $360 \mathrm{~nm}$ and emission at $460 \mathrm{~nm}$. Data at each dilution of MUNANA was analyzed for linear regression and the rate of increase in fluorescence was determined for each dilution. This data was then analyzed with GraphPad Prism (GraphPad Software, CA, USA) by nonlinear regression (Enzyme Kinetics - Michaelis Menten) to determine the Vm and Kmax for each virus.

Oseltamivir Sensitivity. Based on the Neuraminidase Enzyme Kinetics data we determined which combination of virus and MUNANA substrate would result in a signal of approximately 2000 Relative Fluorescence Units (RFU) following 30 minutes of incubation. This required $3.3 \times 10^{4} \mathrm{PFU} / \mathrm{ml}$ of FAV-002/H5N1 and $1 \times 10^{4} \mathrm{PFU} /$ $\mathrm{ml}$ of AGT/H5N1 along with $667 \mu \mathrm{M}$ of MUNANA. Oseltamivir carboxylate (Toronto Research Chemicals, ON, Canada) was diluted in a 10 -fold series $(10 \mu \mathrm{M}$ to $0.01 \mathrm{nM})$ and each corresponding virus was added to each 
dilution and incubated for 30 minutes at $37^{\circ} \mathrm{C}$. The virus/oseltamivir mixture was then added to a round bottom plate containing MUNANA, incubated at $37^{\circ} \mathrm{C}$ for 30 minutes and read using excitation at $360 \mathrm{~nm}$ and emission at $460 \mathrm{~nm}$. Inhibition of enzymatic activity values were then calculated as the percent reduction in RFU relative to control wells containing no oseltamivir.

Postmortem examinations. For birds, timed postmortem examinations were performed on 3, 5 and $7 \mathrm{dpi}$. In addition, postmortem examinations were conducted on moribund birds. Birds were euthanized by exsanguination after being anaesthetized with isofluorane. Samples that included brain, spinal cord, lung, liver, spleen, cecal tonsil, esophagus, trachea, pectoral muscle, kidney, heart, nasal turbinate, pancreas, duodenum, ileum, proventriculus, and thymus were collected. For pigs, timed postmortem examinations were conducted on days $3,4,5$ and 6 post-inoculation, and tissues that included apical, cardiac and caudal lung lobes were collected. For mice, timed postmortem examinations were performed at 3 and $6 \mathrm{dpi}$ and lungs, heart, gut, kidney and spleen were collected. For all species, collected tissues were split and preserved for molecular and microscopic analysis. All tissues collected for microscopic analysis were fixed in 10\% neutral buffered formalin and routinely processed for histopathologic examination. For immunohistochemistry, paraffin tissue sections were quenched for $10 \mathrm{~min}$ utes in aqueous $3 \% \mathrm{H}_{2} \mathrm{O}_{2}$ then pretreated with proteinase $\mathrm{K}$ for 15 minutes. The primary antibody was a mouse monoclonal antibody F26NP9 ${ }^{42}$ specific for influenza A nucleoprotein (NP) and was used at a 1:10,000 dilution for one hour. They were then visualized using a horseradish peroxidase labelled polymer, Envision ${ }^{\circledR}+$ system $^{\circ}$ (anti-mouse) (Dako, USA), reacted with the chromogen diaminobenzidine (DAB). The sections were then counter stained with Gill's hematoxylin.

\section{References}

1. Pasick, J. et al. Reassortant Highly Pathogenic Influenza A H5N2 Virus Containing Gene Segments Related to Eurasian H5N8 in British Columbia, Canada, 2014. Sci. Rep. 5, 9484 (2015).

2. Prosser, D. J. et al. Wild bird migration across the Qinghai-Tibetan plateau: a transmission route for highly pathogenic H5N1. PLoS One. 6, e17622 (2011).

3. Sims, L. D. \& Brown, I. H. Multicontinental epidemic of H5N1 HPAI virus (1996-2007). In Avian Influenza (ed. Swayne, D. E.) 251-286 (Blackwell Publishing, 2008).

4. Keawcharoen, J. et al. Wild ducks as long-distance vectors of highly pathogenic avian influenza virus (H5N1). Emerg. Infect. Dis. 14, 600-607 (2008).

5. Xu, X. Y., Subbarao, K., Cox, N. J. \& Guo, Y. J. Genetic characterization of the pathogenic influenza A/Goose/Guangdong/1/96 (H5N1) virus: Similarity of its hemagglutinin gene to those of H5N1 viruses from the 1997 outbreaks in Hong Kong. Virology 261, 15-19 (1999).

6. Kim, Y. I. et al. Pathobiological features of a novel, highly pathogenic avian influenza A (H5N8) virus. Emerg. Microbes. Infect. 3, e75 (2014).

7. Kim, H. M. et al. Pathogenesis of novel reassortant avian influenza virus A (H5N8) isolates in the ferret. Virology 481, 136-141 (2015).

8. Eagles, D. et al. H5N1 highly pathogenic avian influenza in Southeast Asia. Rev. Sci. Tech. 28, 341-348 (2009).

9. WHO/OIE/FAO. Toward a unified nomenclature system for highly pathogenic avian influenza virus (H5N1). Emerg. Infect. Dis. 14, el (2008).

10. Fries, A. C. et al. Genomic analyses detect Eurasian-lineage $\mathrm{H} 10$ and additional $\mathrm{H} 14$ influenza A viruses recovered from waterfowl in the Central United States. Influenza Other Respir. Viruses 8, 493-498 (2014).

11. Dusek, R. J. et al. North Atlantic migratory bird flyways provide routes for intercontinental movement of avian influenza viruses. PLoS One. 9, e92075 (2014)

12. Lee, D. H. et al. Evidence of intercontinental transfer of North American lineage avian influenza virus into Korea. Infect. Genet. Evol. 11, 232-236 (2011).

13. Pearce, J. M., Ramey, A. M., Ip, H. S. \& Gill, R. E. Jr. Limited evidence of trans-hemispheric movement of avian influenza viruses among contemporary North American shorebird isolates. Virus Res. 148, 44-50 (2010).

14. Lam, T. T. et al. Migratory flyway and geographical distance are barriers to the gene flow of influenza virus among North American birds. Ecol. Lett. 15, 24-33 (2012).

15. Koehler, A. V., Pearce, J. M., Flint, P. L., Franson, J. C. \& Ip, H. S. Genetic evidence of intercontinental movement of avian influenza in a migratory bird: the northern pintail (Anas acuta). Mol. Ecol. 17, 4754-62 (2008).

16. Jeong, J. et al. Highly pathogenic avian influenza virus (H5N8) in domestic poultry and its relationship with migratory birds in South Korea during 2014. Vet. Microbiol. 173, 249-257 (2014).

17. Adlhoch, C. et al. Comparing introduction to Europe of highly pathogenic avian influenza viruses A(H5N8) in 2014 and A(H5N1) in 2005. Euro. Surveill. 19, 20996 (2014).

18. Ip, H. S. et al. Novel Eurasian highly pathogenic avian influenza a H5 viruses in wild birds, Washington, USA, 2014. Emerg. Infect. Dis. 21, 886-890 (2015)

19. Torchetti, M. K. et al. Novel H5 Clade 2.3.4.4 Reassortant (H5N1) virus from a green-winged teal in Washington, USA. Genome Announc. 3, e00195-15 (2015).

20. Kim, H. R. et al. Pathologic changes in wild birds infected with highly pathogenic avian influenza A (H5N8) viruses, South Korea, 2014. Emerg. Infect. Dis. 21, 775-780 (2015).

21. Pulit-Penaloza, J. A. et al. Pathogenesis and transmission of novel HPAI H5N2 and H5N8 avian influenza viruses in ferrets and mice. J. Virol. 89, 10286-10293 (2015).

22. Munier, S. et al. A genetically engineered waterfowl influenza virus with a deletion in the stalk of the neuraminidase has increased virulence for chickens. J. Virol. 84, 940-952 (2010).

23. Lu, B., Zhou, H., Ye, D., Kemble, G. \& Jin, H. Improvement of influenza A/Fujian/411/02 (H3N2) virus growth in embryonated chicken eggs by balancing the hemagglutinin and neuraminidase activities, using reverse genetics. J. Virol. 79, 6763-6771 (2005).

24. Wagner, R., Wolff, T., Herwig, A., Pleschka, S. \& Klenk, H. D. Interdependence of hemagglutinin glycosylation and neuraminidase as regulators of influenza virus growth: a study by reverse genetics. J. Virol. 74, 6316-6323 (2000).

25. Castrucci, M. R. \& Kawaoka, Y. Biologic importance of neuraminidase stalk length in influenza A virus. J. Virol. 67, 759-764 (1993).

26. Hossain, M. J., Hickman, D. \& Perez, D. R. Evidence of expanded host range and mammalian-associated genetic changes in a duck H9N2 influenza virus following adaptation in quail and chickens. PLoS One 3, e3170 (2008).

27. Matsuoka, Y. et al. Neuraminidase Stalk Length and Additional Glycosylation of the Hemagglutinin Influence the Virulence of Influenza H5N1 Viruses for Mice. J. Virol. 83, 4704-4708 (2009).

28. Li, J., zu Dohna, H., Cardona, C. J., Miller, J. \& Carpenter, T. Emergence and genetic variation of neuraminidase stalk deletions in avian influenza viruses. PLoS ONE 6, e14722 (2011). 
29. Katz, J. M. et al. Molecular Correlates of Influenza A H5N1 Virus Pathogenesis in Mice. J. Virol. 74, 10807-10810 (2000).

30. Smith, A. M. \& McCullers, J. A. Molecular signatures of virulence in the PB1-F2 proteins of H5N1 influenza viruses. Virus Res. 178, 146-150 (2013)

31. Pan, M. et al. Human infection with a novel, highly pathogenic avian influenza A (H5N6) virus: Virological and clinical findings. J. Infect. doi: 10.1016/j.jinf.2015.06.009 (2015).

32. Yang, Z. F., Mok, C. K., Peiris, J. S. \& Zhong, N. S. Human infection with a novel avian influenza A (H5N6) virus. N. Engl. J. Med. 373, 487-489 (2015).

33. Choi, Y. K. et al. Studies of H5N1 influenza virus infection of pigs by using viruses isolated in Vietnam and Thailand in 2004. J. Virol. 79, 10821-10825 (2005).

34. Isoda, N. et al. Pathogenicity of a highly pathogenic avian influenza virus, A/chicken/Yamaguchi/7/04 (H5N1) in different species of birds and mammals. Arch. Virol. 151, 1267-1279 (2006).

35. Zhu, W. et al. PB2 protein of A(H7N9) influenza virus increased its virulence in mammalian models. Sci. Rep. 5, 14170 (2015).

36. Chen, H. et al. The evolution of H5N1 influenza viruses in ducks in southern China. Proc. Natl. Acad. Sci. USA 101, 10452-10457 (2004).

37. Yuan, R. et al. Pathogenicity and transmission of H5N1 avian influenza viruses in different birds. Vet. Microbiol. 168, 50-59 (2014).

38. Spackman, E. et al. Development of a real-time reverse transcription PCR assay for type A influenza virus and avian H5 and H7 hemagglutinin subtypes. J. Clin. Microbiol. 40, 3256-3260 (2002).

39. Hoffmann, E., Stech, J., Guan, Y., Webster, R. G. \& Perez, D. R. Universal primer set for the full-length amplification of all influenza A viruses. Arch. Virol. 146, 2275-2289 (2001).

40. Tamura, K. \& Nei, M. Estimation of the number of nucleotide substitutions in the control region of mitochondrial DNA of humans and chimpanzees. Mol. Biol. Evol. 10, 512-526 (1993).

41. Tamura, K., Stecher, G., Petersen, D., Filipski, A. \& Kumar, S. MEGA6: Molecular evolutionary genetics analysis version 6.0. Mol. Biol. Evol. 30, 2725-2729 (2013).

42. Yang, M. et al. Development and application of monoclonal antibodies against avian influenza virus nucleoprotein. J. Virol. Methods 147, 265-274 (2008).

43. Miller, L. C. \& Tainter, M. L. Estimation of LD50 and its error by means of log-probit graph paper. Proc. Soc. Exp. Bio. Med. 57, 261 (1944).

\section{Acknowledgements}

The project was funded by the Canadian Inspection Agency. We would like to thank our animal care staff for their tremendous help in executing animal experiments and pathology unit for processing the tissues for histological analysis.

\section{Author Contributions}

T.J. and V.B. performed preliminary work on field submissions at the BC Animal Health Centre while J.P. or Y.B. coordinated work done at the National Centre for Foreign Animal Disease. D.K. coordinated work at the Public Health Agency of Canada. S.B. wrote the animal use document and coordinated studies in swine. T.H. and B.P. performed the nucleic acid sequencing. M.S., C.C.-B. and A.L. processed samples for analysis. C.E.-H. carried out the histopathological analysis of tissues. Y.B. drafted the initial manuscript and later versions were based on input and suggestions from J.P. Figures were prepared as follows; Figure 1 Y.B., Figure 2 J.P., Figures 3-7 M.S., Figures 8 , 10 and 11 C.E-H., Figures 9 and 12 A.L. All authors contributed to the final submitted version.

\section{Additional Information}

Competing financial interests: The authors declare no competing financial interests.

How to cite this article: Berhane, Y. et al. Pathobiological Characterization of a Novel Reassortant Highly Pathogenic H5N1 Virus Isolated in British Columbia, Canada, 2015. Sci. Rep. 6, 23380; doi: 10.1038/srep23380 (2016).

This work is licensed under a Creative Commons Attribution 4.0 International License. The images or other third party material in this article are included in the article's Creative Commons license, unless indicated otherwise in the credit line; if the material is not included under the Creative Commons license, users will need to obtain permission from the license holder to reproduce the material. To view a copy of this license, visit http://creativecommons.org/licenses/by/4.0/ 